\title{
THE FREQUENCY OF TASTE-BLINDNESS IN WELSH POPULATIONS
}

\author{
SYDNEY A. BEACH \\ Depts. of Statistics and Anthropology. Aberystwyth
}

\section{INTRODUCTION}

Received I I.v.53

The ability to taste certain solutions of phenyl-thio-carbamide in water is sharply differentiated in the human race. This is illustrated by Fisher and Falconer (1947), who present data accumulated over several years at the Galton Laboratory, London. An unequally peaked U-type frequency-histogram is commonly found when the results of any survey are graphed.

It is believed that the ability to taste and not to taste the solution of PTC is caused by a simple single autosomal gene-substitution, $T$ and $t . \quad T$ is believed to be a normal dominant to the recessive, non-taster gene, $t$, therefore the homozygous-dominant, $(T \mathcal{T})$, and the heterozygote $(T t)$, would result in an individual capable of tasting very high dilutions of PTC, whilst only the homozygous-recessive $(t t)$, would result in a non-tasting individual. It has been suggested that this dominance may be incomplete, especially in the male. The various conditions are polymorphic in the human race, very approximately, one person in four being a non-taster in European and whiteAmerican populations. Possible differences may, however, exist between one population and another where some form of isolation, partial or complete, is in force between them. The present research was undertaken to investigate the existence or otherwise of such a possible difference between the general Welsh population and the population of the mountain-moorland of Plynlymon in Wales.

\section{METHOD}

An objective method of correctly determining the threshold value of an individual, with the minimum experimental error, requires some ingenuity. The principle used in the present work was largely that described by Fisher and Falconer. A logarithmic series of dilutions of PTG in water were prepared, from a saturated solution of 1600 parts of PTC in a million parts of water to extremely high dilutions of the order of $3 \frac{1}{8}$ parts in a million. The process employed consisted of first manufacturing the 1600 solution by dissolving the PTC in heated tap-water (it was decided to use tap-water in this instance as the local water used is extremely free from dissolved mineral salts) and then diluting by half for each other solution.

When a solution is found that is sufficiently concentrated for a taste to be apparent, the solution of PTC will have a bitter taste. 
Increasingly concentrated solutions of PTC, from the $3 \frac{1}{8}$ parts in a million to the 1600 parts in a million (for brevity, these will henceforth be referred to as the $3 \frac{1}{8}$ and 1600 solutions, with similar abbreviations for the other concentrations) were given to the subject until a definite taste had been detected. Unless a very strong taste had been noticed in the threshold solution the next strength of solution was given to the subject, increasing any detectable taste already felt, as an insurance that the correct threshold had in fact been found. This process enabled a first approximation to the correct threshold to be obtained.

Harris and Kalmus have recently suggested a refinement on the previously used simple determination of threshold. This addition consists of presenting the subject with eight beakers, randomly arranged, four of which contain the threshold solution, four plain water. If these are correctly separated, the experiment is repeated with a solution of greater dilution, until the subject can no longer correctly separate the beakers; this is then assumed to be the true threshold. It was thought that whilst this procedure is theoretically correct, some experimental difficulties might be encountered in practice that would invalidate the precision of the method. Any impurity, or staleness of the PTC due to storage, would allow a false threshold to be determined. To obviate this difficulty an alternative arrangement was used in the determinations given in this paper, wherein four of the eight beakers contained the threshold solution already roughly determined and the remaining four, the next higher dilution. This ensures as far as possible that the differentiation shall be one of taste for PTC alone.

That differences do occur between the two methods may be seen from table I showing double-determinations on some taster and nontaster subjects.

TABLE I

\begin{tabular}{|c|c|c|c|c|c|c|c|c|c|c|c|}
\hline \multirow{2}{*}{ Threshold } & \multicolumn{4}{|c|}{$q$} & \multicolumn{7}{|c|}{ ot } \\
\hline & A & B & C & D & $\mathrm{E}$ & $\mathrm{F}$ & G & $\mathrm{H}$ & I & $\mathrm{J}$ & $\mathrm{K}$ \\
\hline Harris and Kalmus . & $\frac{35}{3} \frac{5}{2}$ & $3 \frac{1}{8}$ & 61 & 50 & $3 \frac{1}{8}$ & 64 & 61 & $12 \frac{1}{2}$ & 50 & 400 & 800 \\
\hline Beach & $1 \frac{0}{16}$ & 61 & 61 & 400 & $3 \frac{1}{8}$ & 64 & $12 \frac{1}{2}$ & 50 & 800 & 1600 & 1600 \\
\hline
\end{tabular}

It can be seen that in the cases of non-tasters, of both sexes, some appreciable variation is apparent. In some of these estimations of threshold the separation by the Harris and Kalmus method was made without the subject being able to state that a definite taste was present in the PTC solution, other than that it had a "stronger" taste than water. As the taste of PTC never becomes very pronounced in the definite non-taster, any foreign taste present might easily be mistaken for a definite taste, resulting in the correct separation of 
the beakers. This error was made almost completely by non-tasters (i.e. subjects who could not detect a distinct taste in the rough test until solutions of the order of, at least, 400 were reached). The PTG solution in the Harris-Kalmus randomisation was then referred to as "stale", "strong", or as a "chemical solution", even far below their previously determined threshold. It is believed that this may be due to either the almost inevitable slight impurity of the PTC or to a side-effect of the PTC itself, only detectable against pure water solutions. When this effect is minimised, as with the randomisation used above, far more accurate results are obtained.

\section{SAMPLING}

In the general Welsh sample, the subjects tested came from all parts of Wales and were of Welsh ancestry. This latter condition was considered satisfied if both parents were born within the boundaries of Wales. The Plynlymon Moorland sample contained people with
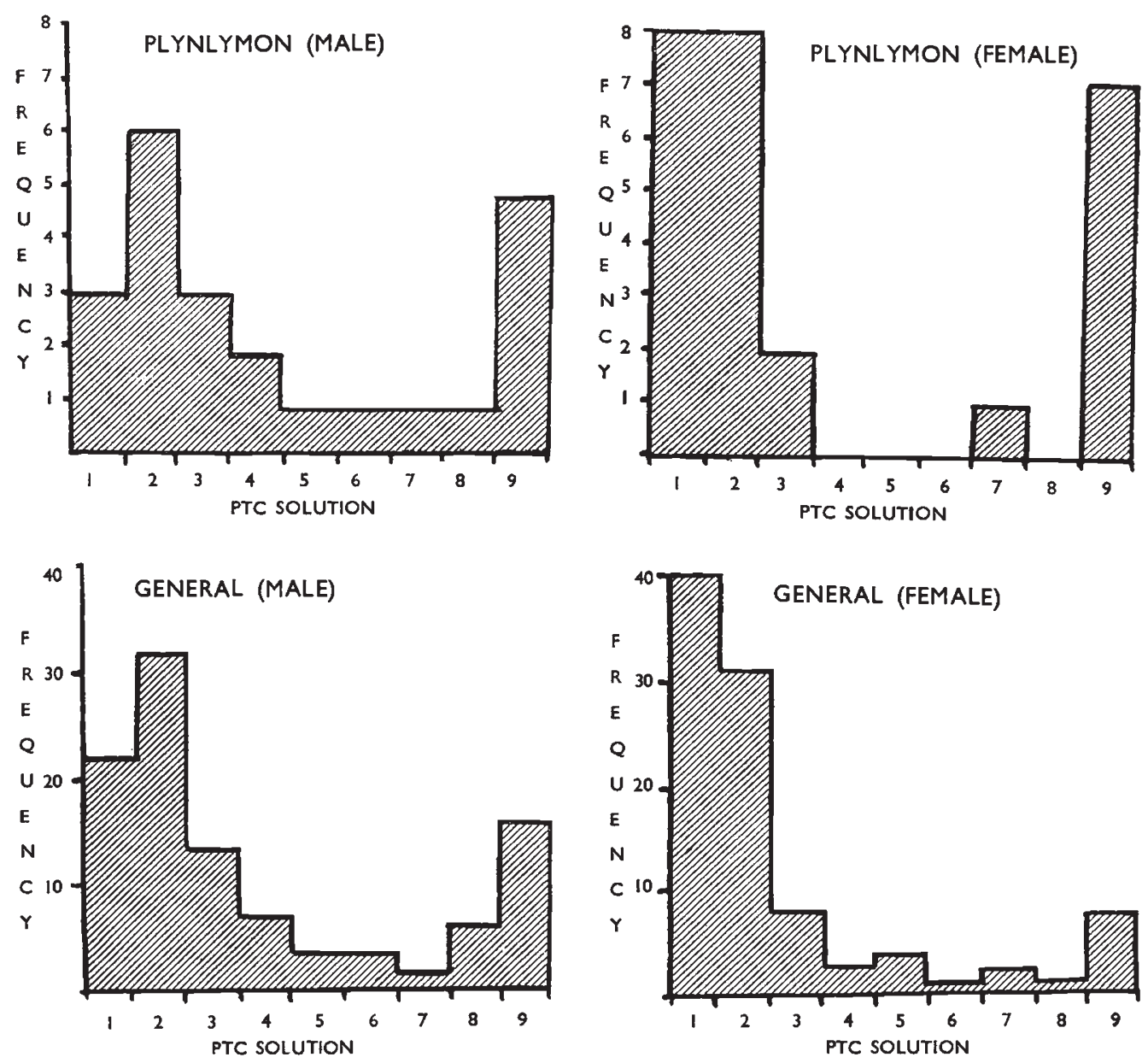
restricted local ancestry only; sometimes it was noted that all eight great grand-parents were born within the limits of the locality.

Both general and Plynlymon samples were collected during the summer of 1952 . For the general Welsh sample, various South and North Wales' towns were visited and places of sampling selected at random; subjects were then selected in a similar manner. It was found that the subjects tested came from all parts of Wales. No particular profession, class or type, sex or age-group was chosen and once a subject had been approached every possible effort was made to include him (or her) in the sample. In this way, only four definite refusals were encountered, out of some 203 individuals actually included in the general sample and none at all in the Moorland sample.

Great care was taken to keep the sampling as random as possible. The day, time of day and place of sampling were all chosen by random-sampling methods, usually by suitable numbering of the possibilities and the use of Fisher and Yates' tables of randomnumbers. If a house was visited, the choice of the inclusion of one person of a family in the sample was left to similar unbiased methods.

\section{RESULTS}

The taste of the threshold solution of PTC commonly found was quite different between the two groups of tasters and non-tasters. The taster described the sensations as similar to quinine, being very bitter indeed, or, almost unanimously in Welsh rural areas, as "Wermod Lwyd".* The comment "Mae'n chwerw iawn!" was often encountered. $\dagger$ The non-tasters varied considerably more than the tasters. Taste sensations among the non-tasters ranged from a definite bitter taste, at the threshold, through a mildly sour or sharp, not unpleasant, tang, to no taste at all in some extreme cases.

The results obtained in this research are now given, corrected for age, in table 2 and in histogram form. The samples are divided up by the nature of the sample (General and Moorland Welsh) and by the sex of the person tested. The number obtained for the thresholds shown are indicated.

It is customary to choose the threshold value that divides the tasters from the non-tasters as that which contains the least number of individuals. Using this criterion, the dividing thresholds become the rather high values of 200 for women and 400 for men. The number of tasters and non-tasters may then be arranged in an hierarchical classification and tested for homogeneity at each stage of the division (table 3 ).

It may be seen that neither of the multiple divisions, either of

* "Wermod Lwyd" - the herb wormwood. Solutions of this herb in water are drunk in Welsh country areas medicinally and for tonic effects, it is very bitter to the taste.

+ "Mae'n chwerw iawn"-it is very bitter. 
sample-locality or of sex, show significant heterogeneity. The value of $\chi^{2}$, for the between-samples heterogeneity, however, is very near the borderline value of significance. The principal reason for this non-homogeneity appears to be the larger percentage of non-tasters

TABLE 2

Classification of samples by sex and locality of sampling

\begin{tabular}{|c|c|c|c|c|c|c|c|c|c|c|}
\hline & \multicolumn{9}{|c|}{ Strength of PTC in solution } & \multirow[b]{2}{*}{ Totals } \\
\hline & $\begin{array}{c}U_{p} \text { to } \\
6 t\end{array}$ & $12 \frac{1}{2}$ & 25 & $5^{\circ}$ & 100 & 200 & 400 & 800 & $\begin{array}{c}1600 \\
\text { and over }\end{array}$ & \\
\hline $\begin{array}{l}\text { Plynlymon (male) } \\
\text { General (male) } \\
\text { Plynlymon (female) } \\
\text { General (female) }\end{array}$ & $\begin{array}{r}3 \\
22 \\
8 \\
40\end{array}$ & $\begin{array}{r}6 \\
32 \\
8 \\
31\end{array}$ & $\begin{array}{r}3 \\
13 \\
2 \\
8\end{array}$ & $\begin{array}{l}2 \\
7 \\
0 \\
3\end{array}$ & $\begin{array}{l}1 \\
4 \\
0 \\
4\end{array}$ & $\begin{array}{l}1 \\
4 \\
0 \\
1\end{array}$ & $\begin{array}{l}1 \\
2 \\
1 \\
2\end{array}$ & $\begin{array}{l}1 \\
6 \\
0 \\
1\end{array}$ & $\begin{array}{r}5 \\
16 \\
7 \\
7\end{array}$ & $\begin{array}{r}23 \\
106 \\
26 \\
97\end{array}$ \\
\hline Totals & 73 & 77 & 26 & 12 & 9 & 6 & 6 & 8 & $3^{5}$ & 252 \\
\hline
\end{tabular}

in the Plynlymon Moorland sample ( 44 against 29 per cent. in the latter). It is possible that larger samples, of both regions would either confirm or deny this heterogeneity more definitely. However, as the heterogeneity of the samples divided by sex is definitely not

TABLE 3

Hierarchical division of samples

\begin{tabular}{|c|c|c|c|c|c|c|c|}
\hline & \multicolumn{2}{|c|}{$\begin{array}{l}\text { Individual } \\
\text { samples }\end{array}$} & \multicolumn{3}{|c|}{ Male and female } & \multicolumn{2}{|c|}{ Total } \\
\hline & $(t t)$ & $n$ & & $(t t)$ & $n$ & $(t t)$ & $n$ \\
\hline $\begin{array}{l}\text { Plynlymon (male) } \\
\text { General (male) } \\
\text { Plynlymon (female) } \\
\text { General (female) }\end{array}$ & $\begin{array}{r}7 \\
24 \\
8 \\
11\end{array}$ & $\begin{array}{r}23 \\
106 \\
26 \\
97\end{array}$ & $\begin{array}{l}\text { (Male) } \\
\text { (Female) }\end{array}$ & $\begin{array}{l}31 \\
19\end{array}$ & $\begin{array}{l}129 \\
123\end{array}$ & \} & $25^{2}$ \\
\hline $\begin{array}{l}\chi^{2} \\
\text { Degrees of freedon } \\
\text { Probability }\end{array}$ & & . & $\begin{array}{l}5 \cdot 5^{877} \\
2 \\
0 \cdot 06\end{array}$ & & & $\begin{array}{l}9174 \\
1 \\
09\end{array}$ & \\
\hline
\end{tabular}

significant, the separate sex-divisions may be merged to give larger numbers to the test of heterogeneity of the place of sampling.

When this is done, the $\chi^{2}$, with one degree of freedom, is 4.4371 which has a probability of between 0.05 and 0.02 , values which may be considered significant. 


\section{DISCUSSION}

The Moorland is a high bleak plateau some fifteen miles from the Welsh coast, with an altitude of from 800 to 1500 feet. The great majority of its population may only be reached by semi-surfaced or unsurfaced cartroads and are thus extremely isolated from the outside world. In addition, it is very highly probable that this isolation was far more complete up to comparatively recent times. Very little intermarriage occurs between the Welsh people of this mountain moorland and the people of the lowlands, consequently, by reason of its comparatively small area, the rate of consanguinity is high. One family was found in which first cousin marriages had occurred for the three previous generations. The people of the moorland seldom leave the area despite the extremely harsh conditions of life, whilst newcomers from the lowland areas seldom stay into the second generation. It is possible, on this account, that the genicconstitution of the people of the moorland might differ, in a statistically significant manner for some particular characters, from the genicconstitution of the Welsh of the lowlands. In this respect, there is some recent evidence of Mourant and Watkins in which the bloodgroup B-gene frequencies of the Black Mountains of Carmarthenshire, the Mynydd Hiraethog of West Denbighshire and the Plynlymon Moorland were far higher than in the surrounding countryside.

It is possible that these results and indeed some of the undoubted differences in expression of the taster-gene, may be explained by some environmental effects. Similar 1 esults have been found in animals and certain insects that indicate that such an hypothesis is, at least, possible in man. It is also possible, that the anomalies that do occur may be better explained by either an alternative gene, possibly an allele of the $T, t$ allelomorphs, or by a modifying factor. Some few exceptions to the simple, single-gene substitution with dominance have been found in the earlier investigations of Snyder, where some " non-taster " $\times$ " non-taster " matings resulted in " taster" children. It is perhaps most likely, however, that these exceptions are either physiological or the result of incomplete expression of the gene.

In this paper, some tentative division into tasters and non-tasters by the usually accepted means of minimal frequency has been adopted. This has been done mostly for comparison purposes. However, it will be apparent that genotypic assumptions from this division are to some unknown extent, arbitrary. With this qualification, the gene-frequencies of the general Welsh population and Plynlymon Moorland Welsh populations for the recessive $t$-gene are 0.4152 (土0.0638) and 0.5533 (土0.I I go) respectively.

In all events, when no account is taken of sex, some significant differentiation is apparent between the Plynlymon Moorland population and that of the general Welsh population for the tasting-ability. 
It is probable, with the above-mentioned reservations, that this differentiation is genetic in character.

\section{SUMMARY}

I. A modified randomisation test for accurate determination of the threshold level of taste for PTC is described.

2. In tests for heterogeneity between the main Welsh population and the population of the Plynlymon Moorland, some non-significant heterogeneity is found between the separate samples but none between the simple divisions by sex.

3. On amalgamation, without regard to sex, significant heterogeneity is found between the two main samples. Their gene-frequencies were $0.4{ }_{1} 5_{2}( \pm 0.0638)$ and 0.5533 ( \pm 0. I I $\left._{90}\right)$ respectively.

\section{REFERENCES}

FISHER, R. A., AND FALCONER, D. S. 1947. Sensory thresholds for solutions of phenylthio-carbamide. Ann. Eugen., 13, pp. 2 I I-222.

HARRIS, H., AND KALMUS, H. I949. The measurement of taste sensitivity to phenylthiourea. Ann. Eugen., 15, pp. 24-31.

MOURANT, A. E., AND WATKIN, I. M. 1952. Blood groups, anthropology and language in Wales and the Western Counties. Heredity, 6, 1 3-36.

FISHER, R. A., AND YATES, F. 1949. Statistical Tables for Biological, Agricultural and Medical Research. 3rd ed. Edinburgh : Oliver and Boyd.

SNYDER, L. H. I 932 . Ohio F. Science., 32, 436-440. 